\title{
Association analysis of the skin barrier gene cystatin $A$ at the PSORS5 locus in psoriatic patients: evidence for interaction between PSORS1 and PSORS5
}

\author{
Yiannis Vasilopoulos ${ }^{1,3,4}$, Kevin Walters ${ }^{1,4}$, Michael J Cork ${ }^{1}$, Gordon W Duff ${ }^{1}$, \\ Gurdeep S Sagoo ${ }^{2}$ and Rachid Tazi-Ahnini ${ }^{*, 1}$
}

\author{
${ }^{1}$ School of Medicine and Biomedical Sciences, University of Sheffield, Sheffield, UK; ${ }^{2}$ Public Health Genetics Unit, \\ Wort's Causeway, Cambridge, UK
}

Family-based analysis has revealed several loci for psoriasis and the locus, PSORS5, on chromosome 3q21 has been found in two independent studies. In this region, cystatin A (CSTA) encodes a skin barrier cystein protease inhibitor found in human sweat and it is over-expressed in psoriatic skin. Three CSTA markers at positions $-190($ g. $-190 \mathrm{~T}>\mathrm{C}),+162(\mathrm{c} .162 \mathrm{~T}>\mathrm{C})$ and $+344(\mathrm{c} .344 \mathrm{C}>\mathrm{T})$ were analysed in 107 unrelated patients and 216 matched controls. There was a significant trend for association with CSTA c.162T $>C$ and psoriasis (odds ratio $(O R)=3.45, P<0.001)$. Analysis of constructed haplotypes showed a highly significant association between disease and CSTA - 190T/ + 162C/ +344C (CSTA TCC) $\left(P=10^{-6}\right)$. In independent study, a TDT analysis in 126 nuclear families confirmed the over-transmission of CSTA TCC $(P=0.0001)$. The presence of statistical interaction between CSTA TCC haplotype and HLA-Cw6 at PSORS1 locus was detected by performing TDT analysis on CSTA haplotypes stratified by the presence or absence of the risk allele at HLA-Cw6 locus. To estimate the disease risk we employed conditional logistic regression on the family data. The CSTA TCC haplotype is only associated with psoriasis in those individuals carrying the risk allele at the HLA-Cw6 locus $(\mathrm{OR}=2.22, P=0.0004,95 \% \mathrm{CI}=1.42,3.49)$. These results represent a major step towards the dissection of genetic factors involved in the pathogenesis of psoriasis.

European Journal of Human Genetics (2008) 16, 1002-1009; doi:10.1038/ejhg.2008.40; published online 26 March 2008

Keywords: Skin barrier; cystatin; PSORS1; psoriasis

\section{Introduction}

Psoriasis is a chronic inflammatory skin disorder characterized by epidermal hyper-proliferation, abnormal keratinocyte differentiation and premature desquamation of the stratum corneum. ${ }^{1,2}$ The prevalence differs with ethnic

*Correspondence: Dr R Tazi-Ahnini, School of Medicine and Biomedical Sciences, University of Sheffield, Beach Hill Road, Sheffield S10 2RX, UK. Tel: + 441142713 785; Fax: + 441142711 711;

E-mail: r.taziahnini@sheffield.ac.uk

${ }^{3}$ Current address: Institute of Immunology, Biomedical Sciences Research Center 'Al. Fleming', Vari, Greece

${ }^{4}$ These authors have contributed equally to this work.

Received 9 July 2007; revised 22 January 2008; accepted 5 February 2008; published online 26 March 2008 origin and geographical location and it ranges from 2 to $5 \%$ in the Caucasian population ${ }^{3}$ to 0.1 to $0.3 \%$ in the Far East $^{4}$ and China. ${ }^{5}$ Early studies proposed a multi-factorial mode of inheritance in which genetic and environmental factors jointly influence the onset and course of psoriasis. ${ }^{6}$ A strong genetic component was confirmed by twin studies $^{7}$ and it has been further proposed that psoriasis is a disease involving gene-gene as well as gene-environment interactions exemplified by streptococcal infection, stress, smoking and physical trauma. ${ }^{8-10}$ During the past decade extensive research effort has focused on identifying psoriasis susceptibility loci, using linkage analysis on large family collections reviewed by Sagoo et al. ${ }^{11}$ However, the only consistently replicated linkage in most of 
these studies was with the HLA region, (PSORS1), on chromosome $6 \mathrm{p} 21.3$ that contains the major histocompatibility complex. ${ }^{12}$ In particular, it was well demonstrated that psoriasis is strongly associated with the human leucocyte-associated antigen HLA-Cw6 and individuals harboring this allele were found to have a 10- to 20-fold increased risk for developing psoriasis. ${ }^{13} \mathrm{~A}$ recent study using recombinant haplotypes retained $H L A-C w 6$ as the risk allele conferring susceptibility to early onset psoriasis. ${ }^{14}$ However, specific involvement of a gene in disease pathogenesis has not yet been established. PSORS5 is the candidate psoriasis susceptibility locus on chromosome 3q21 identified by linkage analysis in a Swedish family cohort $^{15,16}$ (Supplementary Figure 1a). There have been several candidate genes identified in this region, including those encoding two type-I membrane proteins of the immunoglobin superfamily, CD80 and CD86 antigens that were found to interact with CD28 to stimulate signals for Tcell activation as well as the integrin $\beta-5$ gene, which is associated with cell adhesion. Cystatin A, also known as stefin $A$, is another candidate gene in the $3 q 21$ region. It encodes an $11 \mathrm{kDa}$ protein (which corresponds to 98 amino acids). This is an acidic protein (pI 4.5) that is mainly located in the keratohyaline granules of the stratum granulosum and the cornified epithelium of the stratum corneum in the epidermis. ${ }^{17}$ Cystatins are endogenous cysteine protease inhibitors that are found in several types of tissue and body fluid of mammals, plants and microorganisms and their main function is to protect tissues and cells from unfavourable proteolysis and to mediate the mechanism responsible for intra- or extracellular protein breakdown. ${ }^{18}$ Cystatin A has been purified from human epidermis, hair shaft and nail as well as polymorphonuclear granulocytes, but it has also been detected in other tissues such as liver and spleen. ${ }^{19,20}$ The human CSTA gene is composed of three exons of 111,102 and $226 \mathrm{bp}$ in length, separated by two introns of 14 and $3.6 \mathrm{kbp}$, respectively $^{21,22}$ (Supplementary Figure 1b). In a recent study, two polymorphisms have been described within the CSTA gene, one in the promoter region (g.-190C $>$ T) and another in exon 3 (c.344C > T), leading to the replacement of threonine by methionine at amino acid position 96 of the protein sequence (Supplementary Figure 1c). However, genetic analysis of CSTA g. $-190 \mathrm{~T}>\mathrm{C}$ in the CSTA promoter region and CSTA c.344C $>$ T in CSTA exon 3 in a set of 148 nuclear families and 44 multi-affected families failed to show any association or linkage with psoriasis. ${ }^{23}$ In view of the strong evidence for a role of cystatin A in the regulatory events of desquamation and its abnormal expression in psoriatic skin, ${ }^{24,25}$ we have sought to identify novel SNPs within the promoter and the coding regions of the CSTA gene by direct sequencing of PCR products. SNPs at positions g. $-190 \mathrm{~T}>\mathrm{C}$ and c.344C $>\mathrm{T}$ have been confirmed in a British population and a new SNP in exon 2 at position +162 has been identified. The allelic distribution of CSTA g. $-190 \mathrm{~T}>\mathrm{C}$, c. $162 \mathrm{~T}>\mathrm{C}$ and c. $344 \mathrm{C}>\mathrm{T}$ was determined in 107 unrelated patients and 216 matched controls. The frequency of each genetic variant and haplotypes constructed with the three SNPs in cases and controls were analysed. The results were replicated in an independent set of 126 nuclear families.

\section{Materials and methods \\ Patients and controls \\ Unrelated patients and controls A total of 107 Caucasian patients with chronic plaques psoriasis were recruited from the South Yorkshire region of the United Kingdom. Two- hundred and sixty-four healthy control samples, which ethni- cally matched the disease population, were blood donors from the Trend Blood Transfusion Service (Sheffield).}

Psoriatic families One-hundred and twenty-six families with at least one affected member were recruited from Sheffield and Edinburgh regions of the United Kingdom. Altogether data were collected from a total of 395 individuals of whom 190 were affected including 120 chronic plaques; 58 both chronic plaque and guttate; 10 pure guttate; 1 pustular and 1 chronic plaque, guttate and postular. Among 126 families 73 have 1 affected member, 43 have 2 affected members, 9 have 3 affected members and 1 has 4 affected members. A total of 142 out of 190 cases $(\sim 75 \%)$ had a positive family history of psoriasis. All of psoriasis patients as well as the families employed in this study were diagnosed and managed by one consultant dermatologist (MJC) in a specialist psoriasis clinic. Blood samples were collected from unrelated patients, affected and unaffected family members after obtaining their informed consent. This was approved by the Sheffield local ethics committee and conformed to the guidelines set forth in the Helsinki protocol. Genomic DNA was extracted from whole blood, obtained from the above individuals, using standard protocols and stored in 96-well microtiter plates, with each well containing $500 \mu \mathrm{l}$ of DNA $(100 \mathrm{ng} / \mu \mathrm{l})$.

\section{Polymorphism detection within the CSTA sequence} In order to detect potential SNPs within the CSTA gene, both the coding region and its promoter were amplified from 20 psoriasis patients and 20 controls in separate PCR reactions, using primers specific for those regions of the CSTA gene sequence (GenBank no. AB007774). DNA from patients and controls was amplified by PCR carried out in a volume of $25 \mu \mathrm{l}$ containing $100 \mathrm{ng}$ of genomic DNA, one unit Taq polymerase (Qiagen Ltd, West Sussex, UK), $200 \mu \mathrm{M}$ of each dNTP, $\times 1$ Qiagen buffer $(10 \mathrm{mM}$ Tris- $\mathrm{HCl}, 50 \mathrm{mM}$ $\left.\mathrm{KCl},\left(\mathrm{NH}_{4}\right)_{2} \mathrm{SO}_{4}, 15 \mathrm{mM} \mathrm{MgCl}, \mathrm{pH} 8.7\right), 0.6 \mu \mathrm{M}$ of each primer. Samples were subjected to PCR amplification, in a 96-well Peltier thermal cycler (MJ Research, Waltham, MA, USA), using the following parameters: initial denaturation at $94{ }^{\circ} \mathrm{C}$ for $3 \mathrm{~min}$ followed by 45 cycles of denaturation at 
$94{ }^{\circ} \mathrm{C}$ for $30 \mathrm{~s}$, annealing at $58-61^{\circ} \mathrm{C}$ for $30 \mathrm{~s}$ and extension at $72{ }^{\circ} \mathrm{C}$ for $45 \mathrm{~s}$, followed by a final extension step at $72{ }^{\circ} \mathrm{C}$ for $10 \mathrm{~min}$. The PCR primers and optimised conditions are shown in Supplementary Table 6 (Supplementary Table 6). Amplification products were analysed on 1.5\% agarose gels, stained with ethidium bromide (Sigma; $5 \mu \mathrm{g} / \mathrm{ml}$ ) and visualised on a UV transilluminator. The desired bands were excised, passed through columns of glass wool (Sigma) and treated with chloroform and dimethyldichlorosilane, followed by ethanol precipitation. The purified DNA was sequenced using an EBI Prism 377 DNA sequencer (Applied Biosystems, Foster City, CA, USA). To detect possible polymorphisms, the resulting sequences were analysed using CLUSTALW (EBI; http://www.ebi.ac.uk/ CLUSTALW).

\section{CSTA SNP genotyping}

By means of using PCR-restriction fragment length polymorphism analysis (PCR-RFLP) with mutated primers introducing a restriction site for RFLP analysis dependent on the respective genotype, all available cases and control samples were genotyped for the following polymorphisms; CSTA g. $-190 \mathrm{~T}>\mathrm{C}$, c. $162 \mathrm{~T}>\mathrm{C}$ and c.344C $>$ T. Following PCR amplification using parameters described previously (4.2.2), RFLP analysis was performed in a volume of $30 \mu \mathrm{l}$ containing $25 \mu \mathrm{l}$ of the PCR product, $5 \mathrm{U}$ of the selected enzyme and the corresponding manufacturer's buffer at the appropriate temperature overnight (New England Biolabs, Beverly, MA, USA). Digestion fragments were resolved on $3 \%$ agarose gels. In each reaction sequenceconfirmed samples were included as positive and negative controls. Genotyping was assessed independently by two investigators and in case of disagreement assays were repeated.

For T-190C polymorphism, PCR using primers Pro-F

(5'-GAAGACACATCCAGCCAAG-3') and Pro-Rmod

(5'-GGAATTTGGAAGAAAGAGGGGTTGGAGGATGAAC C $_{-188} \mathrm{~A}-3^{\prime}$ ) created a Bsr I site by changing a $\mathrm{T}$ at position of -188 of the promoter sequence to $G$ in the reverse primer. RFLP analysis was performed after incubation with $5 \mathrm{U}$ of Bsr I at $65^{\circ} \mathrm{C}$ overnight. Bsr I did not cut the $-190 \mathrm{~T}$ allele (300 bp) and produced bands of 263 and $37 \mathrm{bp}$ for the $-190 \mathrm{C}$ allele. In the case of the c. $162 \mathrm{~T}>\mathrm{C}$ polymorphism, PCR with primers Ex2-Fmod (5'-GAAGAAAAAACAAATGA GACA $\left._{160} \mathrm{~T}-3^{\prime}\right)$ and Ex2-R (5'-TGAGAGTCCACCACTTG-3') generated an Nde I restriction site by changing a $\mathrm{T}$ at position +160 of the exon 2 sequence to $A$ in the forward primer. Nde I digestion resulted in the generation of two fragments of 214 and $21 \mathrm{bp}$ for the $+162 \mathrm{~T}$ allele, as against a single $235 \mathrm{bp}$ fragment with the $+162 \mathrm{C}$ allele. For the polymorphism, PCR using primers Ex3-F (5'-GACCTGT GGCTCTCTCAC-3') and Ex3-Rmod (5'-GAACACTTTGGGT ACATGCTGCTAAAAGC $\mathbf{G}_{346} \mathrm{C}-3^{\prime}$ ) created a BstUI restriction enzyme site by changing the $\mathrm{G}$ at +346 on the CSTA sequence to a $\mathrm{C}$ on the reverse primer. Bst UI did not cut the
$344 \mathrm{~T}$ allele (228 bp) and produced bands of 198 and $30 \mathrm{bp}$ for 344C. HLA-Cw6 genotyping was performed as described previously. ${ }^{26,27}$ All PCR modified primers and conditions used for the cystatin A PCR-RFLP analysis in this study are summarised in (Supplementary Table 7).

\section{Data analysis}

Single SNP-based analysis Disease and control populations were compared non-parametrically. To investigate the possibility of a dose effect, ORs for the heterozygotes and homozygotes were calculated separately by comparing their risk with that for individuals homozygous for the alternative allele. As a dose effect was evident for the CSTA +162 marker, a $\chi^{2}$-test for trend was carried out, weighted by the number of putative disease susceptibility alleles in each genotype group. For both CSTA-190 and CSTA +344 a $\chi^{2}$ analysis for carriage of the relevant allele was performed.

Linkage disequilibrium and haplotype analyses The standardized coefficient of disequilibrium ( $\mathrm{D}^{\prime}$ ) between all combinations of SNP pairs was assessed using the EMLD software (http://request.mdacc.tmc. edu/ qhuang/Software/pub.htm), which calculates pair-wise linkage disequilibrium (LD) based on SNP genotype data from unrelated individuals. In addition to analyses performed for each individual SNP, haplotypes across all three SNPs of the CSTA gene were also constructed and examined.

Haplotype analyses Haplotypes across all three SNPs of the CSTA gene were also constructed and analysed. The EHPLUS software ${ }^{28}$ was used to generate group-wise haplotype frequencies (only haplotypes with frequencies over 5\% were considered) for the case-control analysis. EHPLUS uses an expectation maximization (EM) algorithm to estimate haplotype frequencies and provides a $\chi^{2}$ statistic for haplotype association with disease.

Family-based association analysis We tested for association between the CSTA haplotypes and psoriasis using the Transmit program (version 2.5). Transmit tests for association between haplotypes and disease by examining the transmission of haplotypes from parents to affected offspring. ${ }^{29}$ A value of 5 for $\operatorname{Var}(O-E)$ is the threshold below which there is doubt about the appropriateness of the $\chi^{2}$ distribution under the null hypothesis. A $\operatorname{Var}(\mathrm{O}-\mathrm{E})$ value less than 5 is viewed as unreliable. The CSTA haplotypes were tested for association with psoriasis in 126 psoriasis families. To examine the evidence for a statistical interaction, the same haplotype analysis was also performed after stratifying on the HLA-Cw6-/+ genotype (presence or absence of the risk allele).

Conditional logistic regression We employed conditional logistic regression (CLR) on the family data to quantify the disease risk for the CSTA TCC haplotypes after 
stratifying by the presence of the risk allele at the HLA-Cw6 locus. Ordinarily one would need sibling controls to undertake CLR, but as we did not have sibling controls available for the CLR analysis we used the method of Cordell $e t a l^{30}$ to construct plausible pseudocontrols for the affected offspring based on the parental haplotypes. This method conditions on the set of transmitted and un-transmitted haplotypes being as observed for the proband. Essentially, at each locus, the pseudocontrols have haplotypes consisting of the haplotypes that were not transmitted from parent to proband. Both the generation of appropriate pseudocontrols and the CLR analysis were undertaken in STATA9. Some of the families in this study had multiple affected offspring. Nuclear families with multiple affected sibs cannot generally be considered independent in the presence of linkage. The non-independence of observations can however be allowed for by the appropriate choice of a robust variance estimator as is available in STATA9. The $P$-values are calculated using the likelihood ratio test for nested models (where we compare our model with the null model that has no covariates).

\section{Results}

Three polymorphisms were detected by direct sequence analysis of PCR products, two of which were also found in a recent study ${ }^{23}$ and a synonymous SNP (c.162T $>$ C; Tyrosine35) in exon 2 of the cystatin A gene, previously suggested in silico and deposited in the Ensembl SNP database (dbSNP ID: 7619433) (Supplementary Figures 1b and c). The genotype distributions for the three polymorphisms tested were found to be in Hardy-Weinberg equilibrium in the control group. A test for carriage of the rare allele was used for both CSTA g. -190T > C and CSTA c.344C $>$ T. Single SNP-based analysis revealed that there was no association between CSTA g. $-190 \mathrm{~T}>\mathrm{C}$ or CSTA
c.344C $>$ T. A dose effect was evident for the CSTA c.162C marker, the homozygous odd ratio (OR) for CSTA c.162C was higher than that the heterozygous (see 'Materials and methods'). A $\chi^{2}$-test for trend was therefore carried out for this locus. An association was detected between CSTA c.162C and psoriasis $(P<0.001)$ where the threshold for significance after adjustment for multiple testing is 0.007 . CSTA c. $162 \mathrm{C}$ confers a high risk for disease OR $=3.45(95 \%$ confidence interval (CI): 2.28,5.22)) (Table 1). LD analysis was performed on the control samples using the EMLD program and the resulting pair-wise $D^{\prime}$ values have shown that the level of LD between three SNPs was moderate to strong. LD between the CSTA c.162T $>\mathrm{C}$ and CSTA g. $-190 \mathrm{~T}>\mathrm{C}$ and the CSTA c.344C $>\mathrm{T}$ was 0.41 and 0.63 , respectively. We then constructed haplotypes using genotypes available for the three markers. The EHPLUS program was used to estimate haplotype frequencies and identify haplotype association with disease (Table 2). From the above data it appears that the haplotype-based analysis confirmed the results of single marker analysis, with respect to the association of the CSTA c.162C variant with psoriasis. After adjustment for multiple testing two haplotypes show a significant association with disease. The CSTA-190T/ + 162C/ + 344C (CSTA TCC) haplotype confers susceptibility, whereas CSTA-190T/ + 162T/ + 344C (CSTA TTC) is under-transmitted. Note that the two haplotypes differ by only a single base at the +162 position, suggesting that CSTA +162 is responsible for most of the observed association.

To confirm our findings, we assessed the association between the CSTA haplotypes and psoriasis by examining the transmission of haplotypes from parents to affected offspring, using the program Transmit on 126 psoriatic families (Table 3). After adjustment for multiple testing, the T-C-C and T-T-C haplotypes provided significant evidence against the null hypothesis of no linkage with the disease ( $P=0.0001$ and 0.0012 , respectively). T-T-C is under-transmitted and T-C-C over-transmitted. Both

Table 1 Single-SNP association analysis of CSTA variants in controls and psoriatic patients

\begin{tabular}{|c|c|c|c|c|c|c|}
\hline CstA SNPs & Common allele & Heterozygotes & Rare allele & Total genotyped & Odds ratio $(95 \% \mathrm{Cl})$ & $P$-value \\
\hline $\begin{array}{l}\text { CstaPro } \\
\text { g. }-190 \mathrm{~T}>\mathrm{C}\end{array}$ & $\begin{array}{c}\text { TT } \\
\text { C: } 162(0.74) \\
\text { PS: } 80(0.69)\end{array}$ & $\begin{array}{c}\text { TC } \\
\text { C: } 53(0.24) \\
\text { PS: } 36(0.31)\end{array}$ & $\begin{array}{c}\text { CC } \\
\text { C: } 3(0.02) \\
\text { PS: } 0(0)\end{array}$ & $\begin{array}{c}\text { Total } \\
\text { C: } 218 \\
\text { PS: } 116\end{array}$ & $0.768(0.45,1.31)$ & 0.298 \\
\hline $\begin{array}{l}\text { CstaEx2 } \\
\text { c. } 162 \mathrm{~T}>\mathrm{C}\end{array}$ & $\begin{array}{c}\text { TT } \\
\text { C: } 87(0.42) \\
\text { PS: } 23(0.21)\end{array}$ & $\begin{array}{c}\text { TC } \\
\text { C: } 91(0.44) \\
\text { PS: } 52(0.46)\end{array}$ & $\begin{array}{c}\text { CC } \\
\text { C: } 29(0.14) \\
\text { PS: } 37(0.33)\end{array}$ & $\begin{array}{c}\text { Total } \\
\text { C: } 207 \\
\text { PS: } 112\end{array}$ & $3.45(2.28,5.22)$ & $<0.001$ \\
\hline $\begin{array}{l}\text { CstaEx3 } \\
\text { c. } 344 \text { C > T }\end{array}$ & $\begin{array}{c}\text { CC } \\
\text { C: } 179(0.68) \\
\text { PS: } 149(0.76)\end{array}$ & $\begin{array}{c}\text { CT } \\
\text { C: } 80(0.30) \\
\text { PS: } 46(0.23)\end{array}$ & $\begin{array}{c}\text { TT } \\
\text { C: } 5(0.02) \\
\text { PS: } 1(0.01)\end{array}$ & $\begin{array}{c}\text { Total } \\
\text { C: } 264 \\
\text { PS: } 196\end{array}$ & $1.505(0.97,2.34)$ & $<0.054$ \\
\hline
\end{tabular}

Abbreviations: $\mathrm{C}$, controls; $\mathrm{Cl}$, confidence interval; OR, odds ratio; $\mathrm{PS}$, psoriatic samples.

Genotype frequencies for each polymorphism are indicated between brackets.

Case-control analysis was performed with 218 controls and 116 patients for CSTA g. -190 T > C, 207 controls and 112 patients for CSTA c. 162 T > C and 264 controls and 196 patients for CSTA C.344 C > T. Significant values are shown in bold. 
Table 2 Cystatin A haplotypes constructed using the EH program for the case-control data

\begin{tabular}{lccccc}
\hline $\begin{array}{l}\text { Cystatin A haplotypes } \\
\text { (T190C-T162C-C344T) }\end{array}$ & Control & Frequency & PS cases & Frequency & $\chi^{2}($ d.f. $=1)$ \\
\hline T-T-C & 222 & 0.547 & 89 & 0.414 & 9.606 \\
T-C-C & 86 & 0.212 & 81 & 0.377 & $\mathbf{0 . 0 0 2 0 8}$ \\
C-C-T & 30 & 0.073 & 20 & 0.095 & 0.783 \\
Remaining & 68 & 0.168 & 24 & 0.114 & 0.0000091 \\
Total & 406 & 1.00 & 214 & 1.00 & 0.395 \\
\hline
\end{tabular}

Haplotype frequencies were compared between case and control groups using the EHPLUS software. Significant values are shown in bold. Please note that these results were obtained from set of 107 unrelated patients and 203 healthy controls.

Table 3 TDT analysis of CSTA g. $-190 \mathrm{~T}>$ C c.162T >C c.344C > T haplotypes in 126 psoriasis nuclear families with 395 individuals including 190 patients using Transmit version 2.5

\begin{tabular}{|c|c|c|c|c|c|}
\hline $\begin{array}{l}\text { Haplotypes } \\
\text { (T190C-T162C-C344T) }\end{array}$ & Observed & Expected & $\operatorname{Var}(O-E)$ & $\chi^{2}($ d.f. $=1)$ & P-value \\
\hline T-T-C & 117.89 & 138.81 & 41.795 & 10.469 & 0.0012 \\
\hline C-T-T & 0.06582 & 2.1094 & 1.0027 & 4.1646 & 0.0412 \\
\hline $\mathrm{T}-\mathrm{C}-\mathrm{C}$ & 120.11 & 96.188 & 38.483 & 14.865 & 0.0001 \\
\hline T-C-T & 1.0199 & 0.52089 & 0.25037 & 0.99463 & 0.3186 \\
\hline Total (d.f. $=7$ ) & - & - & - & 26.142 & 0.0004 \\
\hline
\end{tabular}

Significant values are shown in bold.

Table 4 TDT analysis of CSTA g. - 190T > C c.162T > C c.344C > T haplotypes stratified by absence/presence of the HLACw6 risk allele in 126 psoriasis nuclear families with 395 individuals including 190 patients using Transmit version 2.5

\begin{tabular}{|c|c|c|c|c|c|c|}
\hline $\begin{array}{l}\text { Presence/absence of } \\
H L A-C w 6 \text { risk allelle }\end{array}$ & $\begin{array}{c}\text { Haplotypes } \\
\text { (T190C-T162C-C344T) }\end{array}$ & Observed & Expected & $\operatorname{Var}(O-E)$ & $\chi^{2}($ d.f. $=1)$ & P-value \\
\hline HLA-Cw6(+) & $\begin{array}{l}\text { T-T-C } \\
\text { C-T-C } \\
\text { T-C-C } \\
\text { C-C-C } \\
\text { T-T-T } \\
\text { C-T-T } \\
\text { C-C-T }\end{array}$ & $\begin{array}{l}67.588 \\
0.41184 \\
80.412 \\
2.5882 \\
1 \\
0 \\
16\end{array}$ & $\begin{array}{c}85.467 \\
1.0743 \\
60.495 \\
4.435 \\
2.5043 \\
1.028 \\
12.996\end{array}$ & $\begin{array}{l}25.405 \\
0.26005 \\
23.503 \\
1.9376 \\
1.25 \\
0.5003 \\
5.4745\end{array}$ & $\begin{array}{c}12.583 \\
1.6878 \\
16.877 \\
1.7604 \\
1.8102 \\
2.1122 \\
1.6485\end{array}$ & $\begin{array}{l}0.0004 \\
0.194 \\
0.00004 \\
0.185 \\
0.179 \\
0.146 \\
0.199\end{array}$ \\
\hline HLA-Cw6(-) & $\begin{array}{l}\text { T-T-C } \\
\text { C-T-C } \\
\text { T-C-C } \\
\text { C-C-C } \\
\text { C-T-T } \\
\text { T-C-T } \\
\text { C-C-T }\end{array}$ & $\begin{array}{c}50.745 \\
0.1507 \\
41.255 \\
2.8493 \\
0.1039 \\
1 \\
7.8961\end{array}$ & $\begin{array}{l}51.745 \\
0.6507 \\
39.755 \\
2.8493 \\
1.1039 \\
0.5 \\
7.3961\end{array}$ & $\begin{array}{l}15.262 \\
0.26135 \\
14.267 \\
1.3607 \\
0.5054 \\
0.25 \\
3.6515\end{array}$ & $\begin{array}{l}0.065522 \\
0.95655 \\
0.15771 \\
<0.00001 \\
1.9876 \\
1 \\
0.068465\end{array}$ & $\begin{array}{l}0.79 \\
0.328 \\
0.691 \\
>0.99999 \\
0.158 \\
0.317 \\
0.794\end{array}$ \\
\hline
\end{tabular}

Significant values are shown in bold.

haplotypes CSTA T-T-C and CSTA T-C-C were associated with the disease. We looked for statistical interactions between the psoriasis susceptibility loci at $3 \mathrm{q} 21$ and $6 \mathrm{p} 21.3$ by using Transmit to examine the linkage between cystatin A haplotypes after stratification based on presence/absence of the risk allele at HLA-Cw6. The results strongly support the presence of a statistical interaction as the linkage of the
CSTA TCC and TTC haplotypes depends upon the genotype at the HLA-Cw6 locus (Table 4). The TCC and TTC haplotypes only show evidence of linkage to psoriasis in the presence of at least one copy of the risk allele at the HLA-Cw6 locus. According to this analysis there appears to be a statistical interaction between alleles at the HLA-Cw6 locus and haplotypes at the CSTA locus. 
Table 5 Conditional logistic regression analysis of the CSTA TCC haplotype in the family data stratified by the absence/presence of the HLA-Cw6 risk allele

\begin{tabular}{lccl}
\hline & TCC OR & $95 \% \mathrm{Cl}$ & P-value \\
\hline HLA-Cw6(+) & 2.23 & $(1.42,3.49)$ & $\mathbf{0 . 0 0 0 2}$ \\
HLA-Cw6(-) & 1.07 & $(0.67,1.71)$ & 0.791 \\
\hline
\end{tabular}

Significant values are shown in bold.

To assess the strength of the association between the CSTA TCC risk haplotype and psoriasis in the groups defined by presence or absence of the HLA-Cw6 risk allele, we performed CLR on the haplotypes in the family data by first generating pseudocontrols (see 'Materials and methods') in the two groups separately. The results shown in Table 5 indicate that the CSTA TCC haplotype only increases the risk of psoriasis in individuals carrying at least one copy of the risk allele at the HLA-Cw6 locus $(\mathrm{OR}=2.23, P=0.0002)$. The haplotype confers no increased risk to individuals who are HLA-Cw6- $(\mathrm{OR}=1.07$, $P=0.791$ ). This analysis supports our previous TDT analysis, indicating the presence of a statistical interaction between the CSTA haplotypes and the HLA-Cw6 alleles in the association with psoriasis.

\section{Discussion}

PSORS5, the susceptibility locus for psoriasis as well as other immune-mediated complex diseases, is located at the chromosome $3 q 21$ region. This was defined by allelic association to microsatellite markers. ${ }^{16}$ The PS-risk haplotype is a 5 SNP-marker haplotype identified by Hewett et $a l^{31}$ using SNP markers and TDT analysis, within the 3 q21 region; however no disease-causing function has been attributed to the gene (SLC12A8), including the intronic SNPs. ${ }^{31}$ In this study we therefore focused on a gene (ie CSTA) located within the psoriasis susceptibility region on chromosome 3q21, but outside the 5-SNP marker haplotypes as previously defined. ${ }^{31}$ It is possible that the PS risk haplotype defined by Hewett et $\mathrm{al}^{31}$ is a part of an extended haplotype which does include CSTA TCC. SLC12A8 was the first candidate gene to be investigated in this region and it encodes a potassium/chloride transporter Hewett et $a l^{31}$ have reported an association between SLC12A8 variants and psoriasis in 148 Swedish nuclear families but failed to replicate their findings in 47 multi-affected families. A subsequent study ${ }^{32}$ failed to replicate the SLC12A8 association in 210 German nuclear families, showing only bordeline association with the SLC12A8 rs2228674 marker $(P=0.048)$. Another study conducted in a cohort of northern European psoriasis patients failed to show any association with variants of SLC12A8. ${ }^{33}$ Association of SLC12A8 with psoriasis is not conclusively established and needs further investigation. The evidence for a role of the
CSTA in regulation of the skin barrier and thus, potential for involvement in psoriasis derives from the fact that cystatin A is identical to keratolinin, a cytosolic protein initially described as a substrate for epidermal transglutaminase. CSTA is now believed to be one of the precursors of the cornified cell envelope formed during terminal differentiation of keratinocytes, thereby suggesting that cystatin A expression is associated with keratinocyte differentiation. ${ }^{34}$ While our study was in progress, an association analysis of cystatin A in a large Swedish family cohort showed no association with psoriasis. ${ }^{23}$ On closer inspection, there are at least two good reasons why these contradictory results may have occurred. First, the authors did not study the CSTA c.162T $>$ C polymorphism and power was insufficient to detect the association with CSTA c.162T $>$ C-linked markers, such as CSTA g.-190T $>C$ and/or CSTA c.344C $>$ T. Second, the disease-causing mutation may be different in the two populations. Perhaps CSTA c.162T >C or a locus in LD with it in our sample, but another locus may be pathogenetic in the Swedish population. Another important issue is the interaction between PSORS1 and PSORS5. The disease risk seems to be higher for individuals who carry risk alleles at both CSTA and HLA-Cw6. However, the effect of CSTA appears to be dependent from that of HLA-Cw6 since the effect of both susceptibility and protective CSTA alleles is pronounced only in individuals who carry one or two copies of HLA-Cw6 (Table 4). PSORS1 seems to interact with both PSORS $4^{35}$ and PSORS5 (this study), which could constitute a major step towards the dissection of genetic factors involved in the pathogenesis of psoriasis.

Atopic dermatitis (AD) has also a major susceptibility locus on chromosome $3 \mathrm{q} 21^{36}$ and we recently showed that CSTA is associated with AD. ${ }^{37}$ Interestingly, psoriasis and $\mathrm{AD}$ seem to share several susceptibility loci including the one on chromosome $3 \mathrm{q} 21{ }^{38}$ suggesting that CSTA could be the first common locus for psoriasis and $\mathrm{AD}$ identified so far. Our findings suggest that the synonymous CSTA SNP at position +162 is responsible for the most of the association. CSTA c. $162 \mathrm{~T}>\mathrm{C}$ may be the pathogenetic mutation or lie in strong LD with the causative mutation. Until recently, it was widely accepted that synonymous mutations are selectively neutral and without an effect in gene expression and/or mRNA translation. However, this has proven to not be the case as evidence in favor for a role of synonymous mutations in mRNA stability, and regulation of gene expression comes from reports that small stretches of stem loops are important for the formation of stable elongation complexes as well as for termination of transcription. ${ }^{39-41}$ Also, in the case of the corneodesmosin gene, a synonymous mutation located in an RNA stability motif led to increased stability of the RNA transcript by diminishing the transcript affinity for a $39 \mathrm{kDa}$ RNAbinding protein. ${ }^{42}$ More recently, a silent SNP in the multi-drug resistance 1 gene has been reported to change 
drug and inhibition interactions, suggesting that this synonymous polymorphism may affect co-translational folding of the protein. ${ }^{43}$ These results, taken together, provide strong evidence that a synonymous mutation in exon 2 of the human cystatin A gene is strongly associated with psoriasis in both case-control and family-based association studies and act independently from HLA-Cw6. The evidence for statistical interaction between these two loci is equivocal and needs further investigation. CSTA is a good candidate based in its expression and biological function, but CSTA TCC may just form part of an extended haplotype, which carries the true mutation on this region. Functional tests of this minimal risk haplotype should be performed to identify the true causative mutation (s).

\section{Acknowledgements}

We thank the patients and their families who took part in this study. This work was supported by funding from RTA's DC7559, The Psoriasis Association, The Cecil Kind Memorial Fund and Molecular SkinCare Ltd (now York Pharma). YV was supported by a University of Sheffield PhD studentship. We are grateful to Dr Andrew McDonagh for his helpful comments.

\section{References}

1 Stern RS: Psoriasis. Lancet 1997; 350: 349-353.

2 Barker JN: Pathogenesis of psoriasis. J Dermatol 1998; 25: $778-$ 781.

3 Nevitt GJ, Hutchinson PE: Psoriasis in the community: prevalence, severity and patient's belief and attitudes towards the disease. Br J Dermatol 1996; 135: 533-537.

4 Simons RD: Additional studies on psoriasis in the tropics and in the starvation camps. J Invest Dermatol 1949; 12: 285-294.

5 Yui Yip S: The prevalence of psoriasis in the mongoloid race. J Am Acad Dermatol 1984; 10: 965-968.

6 Lomholt G: Psoriasis, Prevalence, Spontaneous Course and Genetics. Copenhagen: G.E.C. Gad, 1963, pp 31-33.

7 Brandrup F, Hauge M, Henningsen J, Eriksen B: Psoriasis in an unselected series of twins. Arch Dermatol 1978; 114: 874-878.

8 Elder JT, Nair RP, Guo SW et al: The genetics of psoriasis. Arch Dermatol 2001; 130: 216-224.

9 Swanbeck G, Inerot A, Martinsson T, Wahlström J: A population genetic study of psoriasis. Br J Dermatol 1994; 131: 32-39.

10 Tagami H: Triggering factors. Clin Dermatol 1997; 15: 677-685.

11 Sagoo GS, Cork MJ, Patel R, Tazi-Ahnini R: Genome-wide studies of psoriasis susceptibility loci: a review. J Dermatol Sci 2004; 35: $171-179$

12 Sagoo GS, Tazi-Ahnini R, Barker JW et al: Meta-analysis of genome-wide studies of psoriasis susceptibility reveals linkage to chromosome 6p21 and 4q28-q31 in Caucasian and Chinese Hans population. J Invest Dermatol 2004; 122: 1401-1405.

13 Mallon E, Newson R, Bunker CB: HLA-Cw6 and the genetic predisposition to psoriasis: a meta-analysis of published serologic studies. J Invest Dermatol 1999; 113: 693-695.

14 Nair RP, Stuart PE, Nistor I et al: Sequence and haplotype analysis supports HLA-C as the psoriasis susceptibility 1 gene. Am J Hum Genet 2006; 78: 827-851.

15 Samuelsson L, Enlun F, Torinsson A et al: A genome-wide search for genes predisposing to familial psoriasis by using a stratification approach. Hum Genet 1999; 105: 523-529.

16 Enlund F, Samuelsson L, Enerback C et al: Psoriasis susceptibility locus in chromosome region 3q21 identified in patients from southwest Sweden. Eur J Hum Genet 1999; 7: 783-790.
17 Takahashi M, Tezuka T, Katunuma N: Phosphorylated cystatin $\alpha$ is a natural substrate of epidermal transglutaminase for formation of skin cornified envelope. FEBS Lett 1992; 308: 79-82.

18 Barret AJ: The cystatins: a new class of peptide inhibitor. Trends Biochem Sci 1987; 12: 193-196.

19 Takeda A, Kaji H, Nakaya Y et al: Comparative studies on the primary structure of human cystatin As from epidermis, liver, spleen and leukocytes. J Biochem 1989; 105: 986-991.

20 Tsushima $\mathrm{H}$, Ueki A, Mine $\mathrm{H}$ et al: Purification and characterization of a cystatin-type cysteine protease inhibitor in the human hair shaft. Arch Dermatol Res 1992; 284: 380-385.

21 Yamazaki M, Ishidoh K, Kominami E, Ogawa H: Genomic structure of human cystatin A. DNA Seq 1997; 8: 71-76.

22 Takahashi H, Asano K, Kinouchi $\mathrm{M}$ et al: Structure and transcriptional regulation of the human cystatin A gene. J Biol Chem 1998; 273: $17375-17380$.

23 Samuelsson L, Stiller C, Friberg C et al: Association analysis of cystatin A and zinc finger protein 148, two genes located at the psoriasis susceptibility locus PSORS5. J Invest Dermatol 2004; 122: $1399-1400$.

24 Bowcock AM, Shannon W, Du F et al: Insights into psoriasis and other inflammatory diseases from large-scale gene expression studies. Hum Mol Genet 2001; 10: 1793-1805.

25 Kulski JK, Kenworthy W, Bellgard M et al: Gene expression profiling of Japanese psoriatic skin reveals an increased activity in molecular stress and immune response signals. J Mol Med 2005; 83: 964-975.

26 Steinle A, Nossner E, Schendel DJ: Isolation and characterization of a genomic HLA-Cw6 clone. Tissue Antigens 1992; 39: 134-137.

27 Tazi-Ahnini R, Camp NJ, Cork MJ et al: Novel genetic association between the corneodesmosin (MHC S) gene and susceptibility to psoriasis. Hum Mol Genet 1999; 8: 1135-1140.

28 Zhao JH, Curtis D, Sham PC: Model-free analysis and permutation tests for allelic associations. Hum Hered 2000; 50: $133-139$.

29 Clayton DA: A generalization of the transmission disequilibrium test for uncertain haplotypes transmission. Am J Hum Genet 1999; 65: $1170-1177$.

30 Cordell HJ, Barratt BJ, Clayton DG: Case/pseudocontrol analysis in genetic association studies: a unified framework for detection of genotype and haplotype associations, gene-gene and geneenvironment interactions, and parent-of-origin effects. Genet Epidemiol 2004; 26: 167-185.

31 Hewett D, Samuelsson L, Polding J et al: Identification of a psoriasis susceptibility candidate gene by linkage disequilibrium mapping with a localized single nucleotide polymorphism map. Genomics 2002; 79: 305-314.

32 Huffmeier U, Lascorz J, Traupe $\mathrm{H}$ et al: Systematic linkage disequilibrium analysis of SLC12A8 at PSORS5 confirms a role in susceptibility to psoriasis vulgaris. J Invest Dermatol 2005; 125: 906-912.

33 Bowcock AM, Cookson WO: The genetics of psoriasis, psoriatic arthritis and atopic dermatitis. Hum Mol Genet 2004; 1: R43-R55.

34 Zettergren JG, Peterson L, Wuepper KD: Keratolinin: the soluble substrate of epidermal transglutaminase for human and bovine tissue. Proc Natl Acad Sci USA 1984; 81: 238-242.

35 Capon F, Semprini S, Dallapiccola B, Novelli G: Evidence for interaction between psoriasis-susceptibility loci on chromosomes 6p21 and 1q21. Am J Hum Genet 1999; 65: 1798-1800.

36 Lee YA, Wahn U, Kehrt R et al: A major susceptibility locus for atopic dermatitis maps to chromosome 3q21. Nat Genet 2000; 26: $470-473$.

37 Vasilopoulos Y, Cork MJ, Teare D et al: A nonsynonymous substitution of cystatin A, a cysteine protease inhibitor of house dust mite protease, leads to decreased mRNA stability and shows a significant association with atopic dermatitis. Allergy 2007; 62: 514-519.

38 Cookson WO, Ubhi B, Lawrence R et al: Genetic linkage of childhood atopic dermatitis to psoriasis susceptibility loci. Nat Genet 2001; 27: 372-373. 
39 Kashlev M, Komissarova N: Transcription termination: primary intermediates and secondary adducts. J Biol Chem 2002; 277: 14501-14508.

40 Reeder TC, Hawley DK: Promoter proximal sequences modulate RNA polymerase II elongation by a novel mechanism. Cell 1996; 87: 767-777.

41 Ujvari A, Pal M, Luse DS: RNA polymerase II transcription complexes may become arrested if the nascent RNA is shortened to less than 50 nucleotides. J Biol Chem 2002; 277: 32527-32537.
42 Capon F, Allen $\mathrm{MH}$, Ameen $\mathrm{M}$ et al: A synonymous SNP of the corneodesmosin gene leads to increased mRNA stability and demonstrates association with psoriasis across diverse ethnic groups. Hum Mol Genet 2004; 13: $2361-2368$.

43 Kimchi-Sarfaty C, Oh JM, Kim IW et al: A 'silent' polymorphism in the MDR1 gene changes substrate specificity. Science 2007; 315: $525-528$.

Supplementary Information accompanies the paper on European Journal of Human Genetics website (http://www.nature.com/ejhg) 